\title{
CORRESPONDENCE
}

\section{Enhanced recovery from respiratory infection following treatment with a PDE-5 inhibitor: a single case study}

\section{Dear Sirs,}

Current guidelines on treatment of acute lower respiratory tract infection (including acute on chronic exacerbations) ${ }^{1,2}$ consider the oxygenation of the alveolar capillaries as the clinical target. Nevertheless, the physiological function of the lung is to deliver oxygenated blood to the left atrium, a function reduced by the pulmonary arterio-venous (A-V) shunt. Current treatments for recovery from chest disease rely on surrogate outcomes such as forced expiratory volume in one second $\left(\mathrm{FEV}_{1}\right.$ ), even though the hard (and therefore more significant) outcome $\mathrm{e}^{3}$ is patient experience - for example, the time to return to normal activity. This focus on patient-related outcomes is exemplified by the two systematic reviews on quality of life, health status and functional status measurement in COPD published in the September 2011 issue of the PCRJ. 4,5

Therefore, I wish to report the effect of treatment with a phosphodiesterase-5 (PDE- 5) inhibitor on myself when recovering from an atypical chest infection, which resulted in an immediate improvement in exercise tolerance. As a 55 year-old UK NHS general practitioner (GP), I contracted an atypical chest infection requiring hospital admission in June 2011. Four weeks later a close relative died, and the funeral was to be held over 400 miles away. Exercise tolerance had improved only slightly to 100 meters at a slow pace $(1-2 \mathrm{mph})$, and the advice of my own GP and practice partners was that I was unfit to return to work and so, by implication, unable to participate in the funeral.

Having already treated the infection, it was postulated that reducing the $\mathrm{A}-\mathrm{V}$ shunt by reducing the pulmonary arterio-venous pressure gradient might improve systemic oxygenation. PDE- 5 inhibitors, notably sildenafil, are licensed in the treatment of pulmonary hypertension (but not to reduce an apparently normal pulmonary arterial blood pressure). Related agents, PDE-4 inhibitors, have been used in COPD for their antiinflammatory effect. ${ }^{6.7}$ Tadalafil $5 \mathrm{mg}$ (a PDE-5 inhibitor) was available, since samples had been provided for use in patients with erectile dysfunction; though it is not licensed for use in pulmonary hypertension it had the advantage not only of availability but a once-daily dosing schedule.

After discussion with my own GP, treatment with tadalafil $5 \mathrm{mg}$ once-daily led to a reduction in breathlessness and a rapid increase in exercise tolerance to near normal levels, allowing me to travel within 24 hours of starting the medication and being able to walk a mile at a normal walking pace of $3-4 \mathrm{mph}$ two days later. The outcome of the intervention was me being able to participate fully as a close family member of the deceased at his funeral. Subsequent daily treatment with $5 \mathrm{mg}$ tadalafil was continued for four weeks; an attempt to stop treatment after three weeks (over a weekend to avoid occupational impact) was unsuccessful, with a return of symptoms of shortness of breath on exercise and reduced exercise tolerance.

The health and economic costs of recovery from acute lung insults are significant. The total annual cost of COPD to the NHS in 2000-1 was estimated to be $f 491,652,000$ for direct costs only and $f 982,000,000$ including indirect costs, ${ }^{1}$ with much of that expense related to exacerbations: this might be reduced by using PDE-5 inhibitors in addition to current treatments to avoid or shorten hospital admission.

Pharmaceutical trials normally require extensive preparation and funding. This is a single case report of an experiment by the author on himself - a method of scientific investigation with a long and illustrious history... There was symptomatic and functional improvement within 24 hours following treatment with a PDE-5 inhibitor, which required a 4week course of treatment to prevent relapse. If treatment of common lung diseases with PDE- 5 inhibitors is found to be effective in a wider patient group using more formal research methods, there is the potential to reduce substantially the morbidity and health service costs of these conditions.

\section{*Andrew J Ashworth ${ }^{\mathrm{a}}$ \\ a Davidsons Mains Medical Centre, Edinburgh, EH4 5BP, UK \\ *Correspondence: andrew.ashworth@lothian.scot.nhs.uk}

Received 15th January 2012; accepted 17th January 2012; online 27th February 2012

Acknowledgements Dr Ken MacKenzie, my GP, who knows me well and who gave me wise advice throughout my recovery, including taking the view that taking daily tadalafil was likely to do no harm. Dr Patrick McGuigan and Dr Jen Ewen, my partners, who throughout my illness were more focused on my recovery than my return to work. Professor Aziz Sheik for giving comments on an earlier draft. Harvey Thomas Ashworth, my grandson, whose death at 11 years old might have this one tiny positive outcome.

Conflicts of interest The author declares that he has no conflict of interest in relation to this article.

Funding Tadalafil samples had been provided free as part of Lilly's campaign to promote daily dosing for erectile dysfunction.

\section{References}

1. National Clinical Guideline Centre. (2010) Chronic obstructive pulmonary disease: management of chronic obstructive pulmonary disease in adults in primary and secondary care. London: National Clinical Guideline Centre

2. Community management of lower respiratory tract infection in adults SIGN Publication No. 59 ISBN 1899893083 Published June 2002 Updated 16/09/2011

3. Yudkin J, Lipska K, Montori V. The Idolatry of the Surrogate. BMJ. 2011;343d7995

4. Tsiligianni I, Kocks J, Tzanakis N, Siafakas N, van der Molen T. Factors that influence disease-specific quality of life or health status in patients with COPD: a systematic review and meta-analysis of Pearson correlations. Prim Care Respir J 2011;20(3):257-68. http://dx.doi.org/10.4104/pcri.2011.00029

5. Kocks, JWH, Asijee GM, Tsiligianni IG, Kerstjens HAM, van der Molen T. Funcional status measurement in COPD: a review of available methods and their feasibility in primary care. Prim Care Respir J 2011;20(3):269-75. http://dx.doi.org/10.4104/pcrj.2011.00031

6. Compton $\mathrm{CH}$, Gubb J, Nieman R, et al. Cilomilast, a selective phosphodiesterase-inhibitor for treatment of patients with chronic obstructive pulmonary disease: a randomised, dose-ranging study. Lancet 2001;358(9278):265-70. http://dx.doi.org/10.1016/S01406736(01)05481-2

7. Price D, Chisholm A, Ryan D, Crockett A, Jones R. The use of roflumilast in COPD: a primary care perspective. Prim Care Respir J 2010;19(4):342-51. http://dx.doi.org/10.4104/pcrj.2010.00066

(C) 2012 Primary Care Respiratory Society UK. All rights reserved.

http://dx.doi.org/10.4104/pcrj.2012.00016 